\title{
Laparoscopic Management of Benign Ovarian Masses
}

\author{
Rachana Saha, ${ }^{1}$ Chanda Karki ${ }^{1}$ \\ 'Department of Obstetrics and Gynecology, Kathmandu Medical College Teaching Hospital, Kathmandu, Nepal.
}

\section{ABSTRACT}

Introduction: Laparoscopic surgery is one of the most common procedures performed for benign ovarian masses. The aim of the study was to analyze all benign ovarian masses treated laparoscopically to assess safety, feasibility and outcome.

Methods: A prospective study was carried out at Kathmandu Medical College Teaching Hospital, Sinamangal, Nepal. All the patients undergoing laparoscopic surgery for benign ovarian masses from $1^{\text {st }}$ January 2012 to $31^{\text {st }}$ December 2012 were included in the study. The pre-operative findings, intra-operative findings, operative techniques and post-operative complications were analyzed.

Results: Thirty-six patients were taken for the study. Two cases were excluded since intraoperatively they were tubo-ovarian masses. The most common tumor was dermoid cyst $(n=13 ; 38.23 \%)$ and endometriotic cyst $(n=14 ; 41.17 \%)$. Out of 34 cases, five cases of endometriotic cyst $(14.70 \%)$ were converted to laparotomy due to severe adhesions and four cases of endometriotic cyst underwent deroofing surgery. Two cases underwent laparoscopic assisted vaginal hysterectomy with bilateral salphingo-oopherectomy. Successful cystectomies were carried out in 22 cases. None were malignant. Major complications were not noted while minor complications like port-site infection $(n=3 ; 8.82 \%)$ and subcutaneous emphysema $(n=1$; $2.9 \%)$ were present.

Conclusions: Laproscopic management of benign ovarian masses is safe and feasible.

Keywords: benign ovarian masess; cystectomies; laparoscopy.

\section{INTRODUCTION}

The management of the patients who present with ovarian cyst is often controversial especially in reproductive age..$^{1-18}$ Ovarian cysts were often managed by laparotomy and laparoscopic management of ovarian cysts has been explored as an alternative, primarily because of the reduced surgical morbidity, reduction in pelvic adhesions, shorter recovery period and reduced cost. ${ }^{1-18}$ If surgery is indicated, a laparoscopic approach is generally considered to be the gold standard management of benign ovarian masses. ${ }^{1-18}$
The main concern is determination of benign verses malignant nature of the masses pre-operatively and intra-operatively. However, laparoscopic evaluation of equivocal masses on pre-operative assessment can prevent many laparotomies, ${ }^{1-18}$ and with this background, this study aimed to analyze all benign

Correspondence: Dr. Rachana Saha, Department of Obstetrics and Gynecology, Kathmandu Medical College Teaching Hospital, Kathmandu, Nepal. Email: rachana_saha@yahoo.com, Phone: +977. 9841241296. 
ovarian masses treated laparoscopically to assess safety, feasibility and outcome of such surgeries.

\section{METHODS}

A prospective study was conducted in the department of obstetrics and gynecology at Kathmandu Medical College Teaching Hospital from $1^{\text {st }}$ January 2012 to $31^{\text {st }}$ December 2012. All the patients undergoing laparoscopic surgery for benign ovarian masses were taken for study. Excluded from the study were the patients with family history of ovarian carcinoma, fast growing ovarian tumors, bilateral masses with fixity and nodularity, ultrasound findings of mass more than $10 \mathrm{~cm}$, tumors with more than three cysts, tumors with thick irregular septa, papillary or complex tissue projection and presence of ascities and with tumor marker more than $35 \mathrm{lU} / \mathrm{ml}$. Ethical clearance was obtained from the hospital. Informed consent regarding the surgery and special consent for laparotomy was taken. After enrollment, first diagnostic laparoscopy was carried out which included screening of entire pelvis and abdominal cavity. Patients underwent cystectomy, oophorectomy, salpingo-oophorectomy and hysterectomy with salpingo-oophorectomy depending upon the patient profile, clinical presentation, and intra-operative diagnosis. Intra-operative findings, type of surgery, difficulties during surgery, spillage, tissue retrieval and conversion to laparotomies were noted. Histopathology reports were correlated with preoperative and intra operative findings. Patients were followed till two weeks post-surgery.

\section{RESULTS}

Thirty-six patients with benign ovarian masses were taken for laparoscopy. Two patients had tubo-ovarian masses and were excluded from study. The mean age of the patients undergoing laparoscopic surgery was $30 \pm 7.48$ years (mean $\pm S D$ ) with maximum patients in the age group of 25-29 years. Majority $(n=30,83.3 \%$ ) of the patients were parous. There were four complications noted out of 29 laparoscopic cases performed, of which one was subcutaneous emphysema and three had port-site infection. Five cases were converted to laparotomy with conversion rate of $14.7 \%$. The reasons for converting to laparotomy were gross adhesions resulting from severe endometriosis.

\begin{tabular}{|ll|}
\hline $\begin{array}{l}\text { Table 1. Laparoscopic findings of the ovarian tumors } \\
\text { ( } \mathbf{n = 3 6 )} \text {. }\end{array}$ \\
\hline Type & $\mathrm{n}(\%)$ \\
Endometrial cyst & $14(38.9 \%)$ \\
Dermoid cyst & $13(36.1 \%)$ \\
Serous cystadenoma & $7(19.4 \%)$
\end{tabular}

Tubo-ovarian mass $2(5.5 \%)$

Endometrial cyst and dermoid cyst remained the most common tumour. Average diameter of endometrial cyst was found $6.92 \mathrm{~cm}(\min 5 \mathrm{~cm}, \max 10 \mathrm{~cm})$ and that of dermoid cyst $5.69 \mathrm{~cm}(\min 4 \mathrm{~cm}, \max 8 \mathrm{~cm})$.

\begin{tabular}{|c|c|}
\hline Symptoms & n (\%) \\
\hline Pain abdomen & $13(38.2 \%)$ \\
\hline Mass per abdomen & $2(5.8 \%)$ \\
\hline Asymptomatic & 19 (55.8\%) \\
\hline
\end{tabular}

Table 3: Laparoscopic procedures performed $(\mathbf{n}=\mathbf{2 9}$ ).

\begin{tabular}{|ll|}
\hline Type of procedures & $\mathrm{n}(\%)$ \\
$\begin{array}{l}\text { Laparoscopic assisted } \\
\text { vaginal hysterectomy }\end{array}$ & $2(6.9)$ \\
Cystectomy & $22(75.8)$ \\
Deroofing & $4(13.8)$ \\
Salphingo-oophrectomy & $1(3.4)$ \\
\hline
\end{tabular}

Successful cystectomies were in 22 cases. Four cases of endometriotic cyst underwent deroofing surgery.

\section{DISSCUSSION}

Among the laparoscopic procedures, surgeries for adnexal masses are one of the most common indications, ${ }^{11,16}$ at the same time it encompasses many controversies. 8 The reasons may be explained by the uncommon but fatal consequences of ovarian malignancies discovered after operation. 8 Therefore, for the safe and proper application of operative laparoscopy, careful history taking, thorough physical examination, ultrasonography and tumor marker like CA-125 should not be omitted before operation. ${ }^{2,411,16}$ Meticulous evaluation of operation, adequate usage of aspiration and frozen section during the operation, and immediate transition to exploratory laparotomy in suspected malignancy may prevent mistreatment of malignant ovarian cancer. ${ }^{16}$ In our hospital we did not have facility of doing frozen section, but with the pre-operative and intra-operative criteria used none of cases reported turned out to be malignant. The histopathology report correlated with laparoscopic findings. Mettler et al, ${ }^{14}$ concluded that many young patients with non-malignant ovarian lesions can be treated with laparoscopy with the option of immediate conversion to laparotomy or within one week if any ovarian malignancy is suspected. 
In our series the commonest tumor was endometriosis $(n=14)$ and dermoid cyst $(n=13)$. Similar findings have been noted by others. $4,6,7,9,10,14,16$ Ovarian cystectomy is the method of choice in young patients to preserve their fertility. ${ }^{4}$ The opening of the wall and the cyst enucleations using monopolar, bipolar, or endocoagulation is the preferable method followed by extraction in an endobag. ${ }^{4}$ But in our series we did not use endobag and the tissue was retrieved by either enlarging lower secondary port or by making minilap incision. Dermoid cyst can and should be treated laparoscopically and should be performed without spillage so as to prevent chemical peritonitis. ${ }^{4,10}$ In our series, all cases had spillage and none of the case developed chemical peritonitis. We also resorted to vigorous wash after tissue retrieval. In series of Shwaki et $\mathrm{al}^{11}$ they had $50 \%$ spillage rate with no single case of chemical peritonitis after the procedure. They also reviewed 14 studies documenting 470 laparoscopic dermoid cystectomies in which spillage occurred in $310(66 \%)$ cases. The significant post-operative complication were seen in only one case with chronic granulamatous peritonitis occurring nine months postoperatively and recommended strict rules to avoid spillage in dermoid cysts. However if it happens there is no increased morbidity. In Kocak et al, ${ }^{10}$ series of 47 cases the incidence of spillage was $42.5 \%$ and chemical peritonitis was nil.

In the surgical management of endometeriosis using laparoscopy or laparotomy, the main objective is to destroy or remove visible areas of endometriosis and restoring normal anatomy. ${ }^{17,18}$ Laparoscopy has several advantages over laparotomy for patients in particular, faster recovery. ${ }^{17}$ For surgeons laparoscopy offers two primary benefits- magnification and illumination that are particularly useful in diagnosis of endometriosis. ${ }^{17}$ Drainage alone to treat endometrial cyst is not recommended because of high recurrence rate. ${ }^{17,18}$ Performing cystectomy is superior to fenestration and coagulation for pain and cumulative pregnancy rate. ${ }^{17,18}$
Out of 14 cases of endometriosis five cases underwent laparotomy because of severe adhesion. Sucessful cystectomy was carried out in five cases. Deroofing was done in four cases (Table 4). Endometrial cyst still remains an enigma for us and may be with more experience, more successful cystectomies will be carried out. In Park et al, ${ }^{15}$ series of 288 cases had conversion of $6 \%$ in cases of endometrioma and found cystectomy difficult because of adhesion formation. Zupi et $\mathrm{al}^{18}$ commented that adhesions, in cases of endometrioma, occur to uterosacral ligaments, posterior cul- de-sac, rectosigmoid, and sigmoid colon and adhesiolysis is the most difficult step and main limitation to the laparoscopic treatment. The procedure of cystectomy which included stripping is easy on dermoid. Serous and haemorrhagic cyst may introduce notable difficulty, ${ }^{18}$ and in endometriomas in fact, the residual cystic capsule, have to be destroyed using appropriate sources of thermal energy. ${ }^{18}$ In our series of 34 cases we converted five cases into laparotomy and all these cases were of endometriosis and four cases of endometriosis underwent deroofing that is partial cystectomy and fulguration of the cyst wall. However regarding wound closing methods, there are variety of techniques open for discussion, ${ }^{5}$ but we left the wound edges open. There were no major complications noted in this series though the time period was small and case series too was small.

\section{CONCLUSIONS}

Operative laparoscopy is gaining popularity. In this series, strict adherence to pre-operative and intraoperative criteria led to safe and feasible management of benign ovarian masses with laparoscopy and none of the case turned out to be malignant. This series though small would also encourage to uptake laparoscopy in the management of benign ovarian masses in a country like Nepal where operative laparoscopy in field of gynecology is in infancy.

\section{REFERENCES}

1. Thorton KL, Decherney AH. Laparoscopic management of ovarian cysts: an endocrinologist view. Yale J Biol Med. 1991 Nov-Dec;64(6):599-606

2. RCOG Green-top Guideline No.62. RCOG/BSGE Joint Guideline. Management of suspected ovarian masses in premenopausal women. Royal College of Obsetetricians and Gynaecologists. 2011:10-14p.

3. Quinla DK. The laparoscopic management of large ovarian cysts. J Obstet Gynaecol India. 2010 Apr;60(2):152-6.
4. Mettler L, Jacobs VR. Review of laparoscopic management of benign ovarian masses. In: Jain N, editor. State of the art atlas of endoscopic surgery. 1st ed. New Delhi: Jaypee Brothers Medical Publishers (P)LTD; 2004. p. 132-40.

5. Yadav J, Nezhat FR, Tzitzimikas S. Laparoscopic management of adnexal masses. In: Jain N, editor. State of the art atlas of endoscopic surgery in infertility and gynaecology. 1st ed. New Delhi: Jaypee Brothers Medical Publishers (P)LTD; 2004. p.121-31 
6. Wilczynqski JR, Nowinska A, Szpakowski M, Nowak M, Szpakowski A, Wladzinski J, et al. Laparoscopic treatment of benign ovarian tumours. Ginekol Pol. 2006 Jan;77(1):40-7.

7. Lee CL, Soong YK. Laparoscopic management of benign ovarian tumours. J Formos Med Assoc.1993 Mar;92(3):245-8.

8. Mane S, Penketh R. Laparoscopic management of benign ovarian disease. Semin Laparosc surg. 1999 Jun;6(2):104-11.

9. Yuen PM, Yu KM, Yip SK, Lau WC, Rogers MS, Chang AA. Randomized prospective study of laparoscopy and laparotomy in the management of benign ovarian masses. Am J Obstet Gynecol. 1997 Jul;177(1):109-14.

10. Kocak M, Dilbaz B, Ozturk N, Dede S, Altay M, Dilbaz S, et al. Laparoscopic management of ovarian dermoid cysts: a review of 47 cases. Ann Saud Med. 2004 Sep-Oct;24(5):357-60.

11. Shwaki O, Soliman I, Ebrashy A, Sadek ML, Bahnassy A. Laparoscopic management of ovarian dermoid cysts. MEFSJ. 2004;9(1):58-65.

12. Shindholimath VV, G JS, Patil KV, Ammanagi AS. Laparoscopic management of large ovarian cysts at a rural hospital. J Gynec Endoscopy and Surg. 2009 Jul-Dec;1(2):94-7.
13. Mederios LR, Fachel JM, Garry R, Stein AT, Furness S. Laparoscopic versus laparotomy for benign ovarian tumours. Cochrane Database Syst Rev. 2005 Jul 20;(3):CDOO4751.

14. Mettler L, Semm K, Shieve K. Endoscopic management of adnexal masses. JSLS. 1997Apr-Jun;1(2):103-12.

15. Park KH, Chung JE, Kim JY, Lee BS. Operative laparoscopy in treating benign ovarian cysts. Yonsei Med J.1999;40(6):608-12.

16. Yeung PP, Shwayder J, Pasic RP. Laparoscopic management of endometriosis: comprehensive review of best evidence. Journal of Minimally Invasive Gynecology. 2009;16(3)269-81.

17. El-Mowafi DM. Laparoscopic management of endometriosis. Geneva Foundation for Medical Education and Research. 2006 Nov 16

18. Zupi E, Piredda A, Marconi D, Exacoustos C. Laparoscopic management of endometrioma. In: Jain $\mathrm{N}$, editor. State of the art atlas of endoscopic surgery in infertility and gynecology. 1st ed. New Delhi: Jaypee Brothers Medical Publishers(P) LTD; 2004 .p. 173-80. 